\title{
Voluntary Repatriation of the Indochinese Refugees
}

\author{
by Pierre Jambor
}

\begin{abstract}
Voluntary repatriation of refugees has been traditionally considered not only one of the three possible durable solutions, together with resettlement in a third country and local integration, but, actually, the best of those three solutions. Paradoxically, when looking at the Indochinese refugees, it appears that it has been the least applied solution, and also the most controversial. Since 1975, with some exceptions, resettlement in a third country has been the overall solution. A staggering $1,100,000$ Indochinese refugees left for a third country in the past 14 years. This is certainly a major accomplishment and a true sign of international solidarity in the face of a human tragedy of such dimensions.
\end{abstract}

Resettlement on a comparable scale could not, however, go on indefinitely. The cost of resettling a single refugee amounts to several thousands of dollars in the initial phase, and there are additional costs afterwards: it is not only a matter of transportation and initial "start-up" costs, but the costs may go on for several years. If we take a conservative estimate of US $\$ 5,000$ per person, multiplied by the $1,100,000$ mentioned above, we reach a figure in the order of several billion dollars. Furthermore, the Indochinese refugees problem is but one of the refugee situations presently existing. Of course, not all require that such a large number of persons to be resettled, and, in most cases - in Africa, in Central America or for the Afghans - it is a matter of awaiting for a change of circumstances which will enable the refugees to return home. Every year, however, traditional resettlement countries do provide several tens of thousands of resettlement places for refugees all over the world. But the priority in allocating these resettlement slots may vary. The Indochinese refugee problem has been with us for close to fifteen years and it is not perceived today with the same degree of urgency as in 1975-1980. Time and the numbers involved, (that, far from decreasing, have tended to recently increase) explain the reactions by the countries involved, especially those providing first asylum.

A further question has appeared with increasing insistence: to what extent resettlement, which has been seen for years as a panacea, has not become part of the problem? A new concept which has emerged is the "push and pull" factor. In analyzing the reasons which have caused this situation to linger, a distinction has been made between those factors which are linked to the situation (real or perceived) in the country of origin and which "push" people to leave, and those external factors, such as the expectation of a better life, (i.e., increased economic opportunities, better education, better health coverage, etc.) which "pull" people to leave their country. The 1979 International Conference on Indochinese Refugees, linked the provision of first asylum to resettlement in a developed country. This is at the origin of the impressive number of Indochinese refugees resettled, but it may also explain why, in the mind of later arrivals and prospective departees, an expectation of automatic resettlement in the West was created. Some may, therefore, argue that resettlement had turned into the mythical snake that eats its own tail: more refugees, more resettlement, more resettlement, more refugees.

Of course, this element cannot be taken in isolation, but it may contribute to explaining what has euphemistically been called "compassion fatigue".

Since 1975, the overall situation in the region has changed, mostly for the better, but some deep shadows remain. As a result of a local "glasnost," regional relations have improved and some changes have occurred in the governments of the countries of origin. If these trends continue, we can hope that fewer people will leave and more will be willing to return. The picture, however, continues to show dark clouds.

Another concept, which was introduced in the study of the Indochinese refugees phenomenon, was the one of "root causes," and tackling them to solve the problem. Although this notion has been essentially used in a political context, it has acquired relevance when considering the increasingly heard statement that the majority of asylumseekers are "economic migrants," leaving their country because of economic hardship. Continuing in the same line of thought, there was a perception that the renewed outflow was essentially due to economic reasons, that resettlement could not keep pace with the outflow. This provided the justification for increasingly harsh measures, which have been dubbed "humane deterrence." This "humane deterrence" has certainly been deadly for a large number of human beings.

A Chinese proverb says that times of crisis are times of danger and opportunity. It is because of this real danger that there is an opportunity to salvage the threatened principle of first asylum. The occasion was there to review both the achievements and the mistakes of the past and try to come forward with a new approach. It is in the course of this search that the option of voluntary repatriation as the ideal solution has been rediscovered.

As we have seen, the conjunction of two factors - decreased opportunities for resettlement and the changing situation in the country of origin - improved the climate in the region and the realization that old remedies were no cure anymore. Efforts were revived to look at voluntary repatriation as the most appropriate solution, at least for a large number of refugees and asylum-seekers. This, 
however, is easier said than done, as there are a number of conditions which need to be fulfilled. In theory, there are two sets of conditions, at the individual level and at the governmental level.

At the individual level, the first and foremost condition is the best interest of the refugees themselves: this implies that conditions conductive to the return of the refugees exist or be created. They include the existence of peace and security, as well as an economic climate where individuals can fulfill their basic needs. Clearly, such conditions encompass political, economic and social elements, which are the responsibility of the countries of origin.

These conditions must not only exist, they also have to be known by the refugees and asylum-seekers concerned. Unbiased information must be available to the persons concerned.

It is to some extent arbitrary to separate the conditions required at the level of the individuals concerned and at the level of the authorities, as they are the two sides of the same coin. Furthermore, those conditions, as we have listed them - a proper climate, good information, and the voluntary character of the return - appear clear, if not necessarily simple. Reality is infinitely more complex.

The creation of a climate conducive to the return of people can include elements which might put into question the fundamentals on which some governments operate their philosophy and their ideology; these might have conditioned the economic and social orientation which may have been the primary reason for the outflow. Although recent events in Eastern Europe tend to show that nothing is fixed forever, changes of such magnitude take time.

Additionally, in a world which is increasingly a global village, such changes may have to be encouraged by the international community, the superpowers, regional neighbours or economic partners. All these considerations have brought us very far from the strictly humanitarian concerns which, in an ideal world, should be the first and only consideration when looking at a refugee problem.

Good information is the second element in the equation, but it may be only marginally easier to define and then achieve. Good information could be defined as comprehensive and objective information surrounding a possible return. Ongoing debates tend to show that increasing the means of informationsharing has not necessarily meant better information. Lenin stated that information was but one of the elements of a policy and must be used to reach the objectives set by this policy. The use of information to achieve policy objectives - sometimes called propaganda - is not a monopoly of communism. To a greater or lesser extent the temptation exists for governments to use the information for their own purposes. As the Jesuits say, one can also sin by omission. Can information be neutral? Where does neutral information stop and propaganda start? If promotion of voluntary repatriation includes the provision of information of conditions in the country of origin, how can one ensure that such information is both correct and exhaustive?

Turning now to the essential element of "voluntary repatriation," i.e., its voluntary character, this implies that the individual be in a position to express his or her own free will and that his or her decision be respected. Simple enough to say, but much harder to ensure. If the conditions of existence in the refugee camps are excessively harsh, can a decision taken in such a context be considered free? Supposing that we are satisfied that the decision has indeed been taken bearing in mind all the information available and devoid of any external pressure, but, as external observers, we feel that for a number of different reasons, it is not advisable to return, can we preempt the decision of the person concerned and decide on his behalf as to what we feel is best for him? Clearly, we cannot advocate the principle of a decision based on free will and then be the ones not to respect this same will. In the context of the Indochinese refugees, this is not a theoretical question.

There is an additional problem which has recently arisen in the context of the Comprehensive Plan of Action related to the Vietnamese Boat People and approved at the International Conference held in June 1989 in Geneva: traditionally, voluntary repatriation is one of the three durable solutions to benefit refugees. By saying refugees, it implies that the persons concerned are either prima facie (i.e., without the need to go through a refugee determination procedure) refugees, or have been recognized as such after undergoing such a procedure. In the case of the Boat People, the concept of voluntary return is being tentatively expanded to cover those both screened out and those who may not yet have undergone the refugee determination procedure. The implications of such an expansion must still be fully assessed.

Humanitarian refugee law is not a fixed set of universally accepted rules, but rather, a constantly evolving matter, based on existing refugee problems. For its size, and for its political relevance, the Indochinese refugees problem has had and continues to have a major impact on the evolution of refugee law. It has further highlighted the complexities of the subject and continues to be relevant both by its adherence to traditionally accepted rules of conduct as well as for the new issues or the new way to tackle old issues that it has brought to light. A brief presentation of the present situation and of the prospects for the future may help to further highlight the link between the issues discussed above and the plight of the Indochinese refugees. For clarity's sake, however, the three groups, Lao, Khmer and Vietnamese, must be treated separately.

Organized voluntary repatriation for the Lao started in 1980 . It was, however, very slow: from 1980 to 1988 , some 3,400 repatriated voluntarily. Since January 1989 over 1,200 more have returned. It has been agreed that over 300 per month could return, and this figure will hopefully be increased to 500 in the near future. This dramatic improvement is due to a number of reasons: changes in the country of origin, improved bilateral Lao-Thai relations, and an active promotion campaign on the part of the UNHCR. As for the return, the Lao authorities make no distinction between the voluntary repatriates and the involuntary return of the screened-out. They all benefit from the same treatment. It must also be noted that a refugee status determination procedure has existed since 1985. Prior to this procedure, there were some 3,000 to 4,000 arrivals per month. Presently, they number some 3,000 to 4,000 per year. The consequences of the establishment of a screening procedure are far-reaching. First, resettlement was the only durable solution available, but it was available to all new arrivals only to the extent that they were all considered as refugees. It would, therefore, appear that 
severing the link between reaching Thailand and expecting resettlement in the West has decreased considerably the "pull factor." The screening procedure has, at the same time, contributed to the safeguard of asylum and the protection of refugees while discouraging people without a well-founded fear of persecution to flee their country and languish in refugee camps. Furthermore, for the first time ever, in a region where only two countries are signatories to the International Instruments, acceptance and use of established procedures in the treatment and protection of asylumseekers have been adopted. This in itself is a remarkable and far-reaching accomplishment.

With respect to Khmer refugees, the only known large voluntary repatriation operation took place in 1980 and concerned some 9,000 persons. While it was clear at the time that they were fully aware of the dangerous situation existing in the area where they wished to return and they indeed wanted, of their own free will, to return -, this operation was the source of great polemics on the part of those who felt that, whatever the decision of the people themselves, they should not be allowed to return.

Since then, and apart for a handful of people, there has been no voluntary repatriation as such. Such a large-scale operation would benefit the border population, numbering some 300,000 . They are called displaced persons rather than refugees, but it has been agreed that they should benefit, when the time comes, from the treatment reserved to refugees under a large-scale repatriation operation.

It has also been agreed that voluntary repatriation would be the best solution for the large majority and, to our knowledge, that same majority wishes to repatriate when the time comes. At present, however, the conditions conductive to repatriation do not appear to exist. Observers are also disturbed by the way information provided to the border population is lacking both in accuracy and exhaustiveness. It is not easy, in the present situation, to determine what is indeed, accurate and exhaustive information. In a conflict situation, information is part of "psychological warfare" and, as such, is the subject of much manipulation. Two other issues must also be considered, as they are intimately linked to those developed above. While there is a consensus that an eventual voluntary repatriation will be ideal for the majority of the people, there must be an equal consensus that those who may decide, be it temporarily or permanently, not to repatriate, be allowed to do so. Voluntary repatriation without voluntary non-repatriation would be void of meaning.

By the same token, while it is generally agreed that the situation in the country of origin is presently not conducive to large-scale return, and that a comprehensive settlement may indeed be the key, any person or group of any size who, knowing the situation to the extent possible, freely, decide to return, should not face the obstacle of others determining for them, and for whatever purpose, that now is not the right time. This however, is easier said than done.

On the issue of repatriation, it is the Vietnamese refugees, not necessarily the largest in size, that has given rise to heated and emotional debates and has also been a source of major concern to those humanitarian organizations involved in their protection and assistance. They are the only group which has sought asylum in a large number of countries, primarily in South East Asia. They are also the only group which has benefitted from a blanket recognition of their refugee status for almost fifteen years since the events that gave rise to their fleeing their country of origin. But it sowed the seeds of the crisis that bloomed in 1987-1988 and led to the 1989 International Conference. By linking, in 1979, first asylum - which is a fundamental principle - to the provision of a technical solution, i.e., resettlement, the principle has been reduced to depend on the success of the technical solution: asylum was as good as resettlement; a decrease in one would threaten the other. Furthermore, resettlement is the only solution applicable, has created an expectation and become almost an acquired right. The drama of resettlement, which was only belatedly perceived, was that it was the equivalent of digging a hole in the sand: the more one digs, the more sand falls in the hole. Clearly, resettlement could not any more keep up with the rate of arrivals. The reaction of the first asylum countries was to question the principle of first asylum. Concern for loss of life and the sufferings of thousands, as well as the seeming endlessness of the problem, brought all concerned to the 1989 International Conference. A Comprehensive Plan of Action (CPA) was endorsed. It is composed of a set of measures, which include unequivocally the reaffirmation of the principle of first asylum, the establishment of a refugee screening procedure and the active promotion of voluntary repatriation. The continuing high number of arrivals may be explained by the fact that one cannot, overnight, hope to stop a train which has been running full speed for fourteen years. It is also true that the emotional content of the issue is far higher than for other refugee groups. The screening procedure, which is internationally accepted and successfully implemented for the Lao, for instance, meets with resistance by some perhaps well-meaning but ultimately misguided groups when it comes to the Vietnamese. There is greater resistance still to the corollary of any refugee determination procedure, the treatment of screened out.

In order to overcome a potential failure of the CPA, which would have disastrous consequences both for the Vietnamese asylum-seekers and regarding the principle of first asylum, discussions are underway to extend the benefit of voluntary return to include those not having yet undergone the refugee status determination procedure as well as to those having already been screened out. This is, of course, an exceptional and transitory measure, which aims at preserving the hardly won consensus. These efforts have already met with some success: close to one thousand have already returned and over 1,100 applicants are in the pipeline. If the Lao experience is a lesson, we can expect that, albeit slow to start, the repatriation exercise will pick up steam and become a major element in solving a long-standing problem. Within an acceptable time frame, a chance must be given for these efforts to succeed. The CPA represents the light at the end of the tunnel, a long and dark tunnel.

Pierre Jambor is the UNHCR representative in Bangkok. This paper reflects the personal views of its author, and not necessarily those of the organization for which he works. 